Passagens. Revista Internacional de História Política e Cultura Jurídica

Rio de Janeiro: vol. 7, no..1, janeiro-abril, 2015, p. 172-177.

DOI: 10.5533/1984-2503-20157109

\title{
LITURATERRA [Resenha: 2015,1]: Mandrágoras, clínica psicanalítica: Freud e Winnicott
}

Gisálio Cerqueira Filho'

\section{LITURATERRA [Resenha: 2015,1]}

As resenhas e passagens literárias em Passagens. Revista Internacional de História Política e Cultura Jurídica são editadas na seção cujo título apropriado é LITURATERRA.

Trata-se de um neologismo criado por Jacques Lacan ${ }^{2}$, para dar conta dos múltiplos efeitos inscritos nos deslizamentos semânticos e jogos de palavras tomando como ponto de partida o equívoco de James Joyce quando desliza de letter (letra/carta) para litter (lixo), para não dizer das referências a Lino, litura, liturarios para falar de história política, do Papa que sucedeu ao primeiro (Pedro), da cultura da terra, de estética, direito, literatura, inclusive jurídicas - canônicas e não canônicas - ainda e quando tais expressões se pretendam distantes daquelas religiosas, dogmáticas, fundamentalistas, para significar apenas dominantes ou hegemônicas.

\section{LITURATERRA [Reseña: 2015,1]}

Las reseñas e incursiones literarias en Passagens: Revista Internacional de Historia Política y Cultura Jurídica son publicadas en una sección apropiadamente titulada LITURATERRA.

Se trata de un neologismo creado por Jacques Lacan para dar cuenta de los múltiples efectos introducidos en los giros semánticos y juegos de palabras que toman como punto de partida el equívoco de James Joyce cuando pasa de letter (letra/carta) a litter (basura), sin olvidar las referencias a Lino, litura, liturarios para hablar de historia política, del Papa que sucedió al primero (Pedro), de la cultura de la terre (tierra), de estética, de derecho, de literatura, hasta jurídica - canónica y no canónica. Se da prioridad a las contribuciones distantes de expresiones religiosas, dogmáticas o fundamentalistas, para no decir dominantes o hegemónicas.

\footnotetext{
${ }^{1}$ Professor Titular de Teoria Política da Universidade Federal Fluminense. Editor de Passagens. Revista Internacional de História Política e Cultura Jurídica. E-mail: gisalio@superig.com.br

${ }^{2}$ Lacan, Jacques (2003). Outros Escritos. Tradução Vera Ribeiro; versão final Angelina Harari e Marcus André Vieira; preparação de texto André Telles, Rio de Janeiro: Zahar, p. 11-25. [Lacan, Jacques (2001). Autres Écrits, Paris: Éditions de Seuil]
} 


\section{LITURATERRA [Review: 2015,1]}

The reviews and literary passages in Passagens. International Journal of Political History and Legal Culture are published in a section entitled LITURATERRA [Lituraterre]. This neologism was created by Jacques Lacan $^{3}$, to refer to the multiple effects present in semantic slips and word plays, taking James Joyce's slip in using letter for litter as a starting point, not to mention the references to Lino, litura and liturarius in referring to political history, to the Pope to have succeeded the first (Pedro), the culture of the terra [earth], aesthetics, law, literature, as well as the legal references - both canonical and non-canonical - when such expressions are distanced from those which are religious, dogmatic or fundamentalist, merely meaning 'dominant' or 'hegemonic'.

\section{LITURATERRA [Compte rendu: 2015, 1]}

Les comptes rendus et les incursions littéraires de la Revue internationale d'histoire politique et de culture juridique Passagens sont publiés dans une section au titre on ne peut plus approprié, LITURATERRA. II s'agit d'un néologisme proposé par Jacques Lacan pour rendre compte des multiples effets inscrits dans les glissements sémantiques et les jeux de mots, avec comme point de départ l'équivoque de James Joyce lorsqu'il passe de letter (lettre) à litter (détritus), sans oublier les références à Lino, litura et liturarius pour parler d'histoire politique, du Pape qui a succédé à Pierre, de la culture de la terre, d'esthétique, de droit, de littérature, y compris juridique - canonique et non canonique. Nous privilégierons les contributions distantes des expressions religieuses, dogmatiques ou fondamentalistes, pour ne pas dire dominantes ou hégémoniques.

\section{文字国 [图书梗概:2015,1]}

\section{PASSAGENS电子杂志在“文字国”专栏刊登一些图书梗概和文学随笔。PASSAGENS一}

国际政治历史和法学文化电子杂志开通了“文字国”

专栏。“文字国”是法国哲学家雅克 . 拉孔的发明, 包涵了语义扩散, 文字游戏, 从爱尔兰作家詹姆斯. 乔伊斯 的笔误开始, 乔伊斯把letter (字母/信函)写成了litter (垃圾), 拉孔举例了其他文字游戏和笔误, lino, litura, liturarios, 谈到了政治历史, 矢于第二个教皇(第一个教皇是耶稣的大弟子彼得), 关于土地的文化 [Cultura一词多义, 可翻译成文化, 也可翻译成农作物], 拉孔联系到美学, 法学,文学, 包括司法学一 古典法和非古典法, 然后从经典文本延伸到宗教, 教条, 原教旨主义, 意思是指那些占主导地位的或霸权地位的事物。

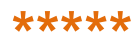

\footnotetext{
${ }^{3}$ Lacan, Jacques (2003). Outros Escritos. Translation by Vera Ribeiro; final version by Angelina Harari and Marcus André Vieira; edited by André Telles, Rio de Janeiro: Zahar, p. 11-25. [Lacan, Jacques (2001). Autres Écrits, Paris: Éditions de Seuil]
} 


\section{Franco, Sergio de Gouvêa; Berlinck, Manoel Tosta; Wondracek, Karin Hellen Kepler (2013). Mandrágoras, clínica psicanalítica: Freud e Winnicott, São Paulo: Primavera Editorial. 176 p.}

\section{Gisálio Cerqueira Filho}

No volume Mandrágoras, clínica psicanalítica: Freud e Winnicott. São Paulo: Primavera Editorial, 2013, três psicanalistas com atividade clínica já consolidada comparecem para discutir entre si aspectos presentes no pensamento de Sigmund Freud e Donald W. Winnicott. O trio de autores (Sergio de Gouvêa Franco, Manoel Tosta Berlinck e Karin Hellen Kepler Wondracek) dialoga entre si há anos no Laboratório de Psicopatologia Fundamental do Programa de Estudos Pós-Graduados em Psicologia Clínica da Pontifícia Universidade Católica de São Paulo (PUC-SP).

O primeiro autor tem formação em engenharia, com mestrado também em engenharia no Instituto de Pesquisas Energéticas e Nucleares - USP. Estudou filosofia e religião com um segundo mestrado no Regent College, Canadá, doutorado em filosofia da educação pela Universidade Estadual de Campinas - UNICAMP, com tese recebida com distinção e louvor. Já o segundo possui bacharelado em Ciências Sociais pela Fundação Escola de Sociologia e Política de São Paulo (1958-1961), Mestre em Ciências Sociais pela Fundação Escola de Sociologia e Política de São Paulo (1964), Ph.D. (Development Sociology) pela Cornell University (1969). Professor de Sociologia do Instituto de Filosofia e Ciências Humanas (IFCH) da Universidade Estadual de Campinas (UNICAMP) (19721992). Diretor do IFCH da UNICAMP (1972-1976). Sócio fundador do Centro Brasileiro de Análise e Planejamento (CEBRAP) e atual presidente da Associação Universitária de Pesquisa em Psicopatologia Fundamental (AUPPF). E finalmente o terceiro autor, Karin Hellen Kepler Wondracek, possui graduação em Psicologia pela Pontifícia Universidade 
Católica do Rio Grande do Sul (1981), mestrado (2002) e doutorado (2010) em Teologia pela Escola Superior de Teologia (EST). Realizou estágio no exterior pela CAPES na Friedrich-Alexander Universität Erlangen-Nürnberg e estudos complementares na Universidade de Freiburg e no Centro de Filosofia da Universidade Católica Portuguesa.

À parte a formação distinta dos autores, todos eles tem formação psicanalítica e praticam a clínica. Isso conferiu a eles um diálogo clínico fascinante e fecundo porque de um lugar rigorosamente inter e multidisciplinar onde a experiência teórico-clínica fala a partir do conhecimento múltiplo.

O título já demonstra esse desejo dos autores, pois MÁNDRAGORAS é uma planta da família das Solanaceae, de origem eurasiana, a que se atribuem propriedades medicinais. "Fala-se de um efeito analgésico, alucinógeno e, sobretudo, de supostos efeitos afrodisíacos" ${ }^{4}$. William Shakespeare também faz menção à planta em Romeu e Julieta.

E a mesma expressão fala ao título de uma peça $A$ Mandrágora, de Nicolau Maquiavel, onde a análise política e relacionada aos aspectos sociais e econômicos, aponta também para uma viva abordagem psicológica. A Mandrágora, de Maquiavel, uma comédia escrita no início do século XVI, talvez 1515, desenvolve-se em torno de sete personagens: a) Ligúrio - um homem que que decidiu alcançar seus objetivos de qualquer maneira. b) Calímaco - jovem culto, que nos é apresentado com virtuoso. c) Siro - fiel servidor do jovem Calímaco. d) Lucrécia - uma linda jovem que vive para seu companheiro e cuja vontade está acoplada principalmente à ética religiosa. e) Messer Nicia - marido de Lucrécia, cuja representação tende à sua própria anulação e inutilidade. f) Sóstrata - mãe de Lucrécia, personifica a ingenuidade em pessoa. g) Frei Timóteo - um sacerdote da Igreja, mas que é apresentado como corrupto. O ponto central da peça está na gravidez desejada por Lucrécia, mas não a qualquer custo. Todavia, Calímaco Guadagni, recém chegado de Paris, imagina a ideia de possuir sexualmente Lucrecia. Para tal contará com a ajuda do seu servidor Siro. Então Messer Nicia, instigado por Ligúrio, aceita os préstimos de Calímaco que, disfarçado de médico, oferece ao marido uma poção mágica visando provocar a desejada gravidez. Mas alguém haverá de substituir Messer Nicia na hora da cópula. A chave da solução está na

\footnotetext{
${ }^{4}$ Ver Introdução do livro referido, p.7.
} 
Mandrágora, a raiz milagrosa que, no mesmo instante em que possibilitará a fecundação de Lucrécia, matará seu provisório parceiro de cama.

Que nas suas linhas mais gerais tal temática tenha sido retomada pelo escritor e crítico de cinema Paulo Emílio Salles Gomes (1916-1977) no seu "Três Mulheres de Três PPPES", especialmente em "Parte I: Duas Vezes com Helena" ${ }^{5}$ confirma o interlúdio entre a crítica social corrosiva; no caso, da burguesia paulista de meados do século XX, e o foco preciso nos conflitos psicológicos. Leve-se em consideração, inclusive, o fato de Paulo Emilio ter sido o primeiro brasileiro a ser analisado por Jacques Lacan.

Mandrágoras é, pois uma senha para os sentimentos fundamentais do humano já presentes na cultura antiga e renascentista que continuam a produzir ecos na cultura contemporânea.

A obra de Sérgio Gouvêa Franco e co-autores está dividida em duas secções: I) relativa a Freud. II) relativa a Winnicott. Diga-se já que a escritura é clara e elegante, 0 que permite uma fruição permanente ao lado da reflexão interpretativa.

Embora os artigos já tenham sido publicados em periódicos científicos como a Revista Latino-americana de Psicopatologia Fundamental, Pulsional Revista de Psicanálise, Revista Estudos de Religião, Revista Ágora e no site da AUPPF, o livro justifica-se, pois facilita o acesso em bloco aos ensaios e demonstra de forma clara o trabalho coletivo na reflexão e produção científica no campos da psicanálise, o que não é trivial,

\section{Parte I}

Esta secção está referida a seis casos clínicos onde a intervenção de Sigmund Freud é referência básica, mas tratada à luz de diversos vetores que ensejam efeitos tanto na transferência quanto na contratransferência.

Aqui, o ensaio mais criativo me pareceu o primeiro, intitulado "Freud e o caso AB: entre a esperança e a ruína", sendo vai assinado em co-autoria com KarinWondracek.

\section{Parte II}

Sem renunciar a Freud, mas convocando Winicott para as suas reflexões mais instigantes, os autores propõem o manejo clínico em conexão com quatro mantras da

\footnotetext{
${ }^{5}$ Ver a edição da Cosac Naify, Organização e Pósfácio de Carlos Augusto Calil, São Paulo, 2007.
} 
clínica contemporânea: o viver criativo (buen vivir !?), o brincar, a criatividade e os denominados "pacientes difíceis". São quatro temas desafiadores e tratados na perspectiva da busca constante da alegria de viver onde o espontâneo emerge de forma eruptiva e inesperada. Aqui, a vã glória do poder pode enfim renunciar à sua vanglória de poder, pois, afinal, temos a arte para não morrer (encharcado) na verdade. ${ }^{6}$

${ }^{6}$ Friedrich Nietzsche (1968). The Will to Power, New York: Random House Inc. 